\title{
Role of gap junctions in regulation of progesterone secretion by ovine luteal cells in vitro
}

\author{
Ewa Borowczyk ${ }^{1}$, Mary Lynn Johnson ${ }^{1,2,3}$, Jerzy J Bilski ${ }^{1,2}$, Magda A Bilska ${ }^{1}$, Dale A Redmer ${ }^{1,2,3}$, \\ Lawrence P Reynolds ${ }^{1,2,3}$ and Anna T Grazul-Bilska ${ }^{1,2,3,}$ \\ ${ }^{1}$ Department of Animal and Range Sciences, ${ }^{2}$ Cell Biology Center and ${ }^{3}$ Center for Nutrition and Pregnancy, North \\ Dakota State University, Fargo, North Dakota 58105, USA \\ Correspondence should be addressed to A T Grazul-Bilska; Email: anna.grazul-bilska@ndsu.edu
}

\begin{abstract}
To evaluate the role of gap junctions in the regulation of progesterone secretion, two experiments were conducted. In Experiment 1 , luteal cells obtained on days 5,10 , and 15 were cultured overnight at densities of $50 \times 10^{3}, 100 \times 10^{3}, 300 \times 10^{3}$, and $600 \times$ $10^{3}$ cells/dish in medium containing: (1) no treatment (control), (2) LH, or (3) dbcAMP. In Experiment 2, luteal cells from days 5 and 10 of the estrous cycle were transfected with siRNA, which targeted the connexin (Cx) 43 gene. In Experiment 1, progesterone secretion, Cx43 mRNA expression, and the rates of gap junctional intercellular communication (GJIC), were affected by the day of the estrous cycle, cell density, and treatments (LH or dbcAMP). The changes in progesterone secretion were positively correlated with the changes in Cx43 mRNA expression and the rates of GJIC. Cx43 was detected on the luteal cell borders in every culture, and luteal cells expressed 3 3 -hydroxysteroid dehydrogenase. In Experiment 2, two Cx43 gene-targeted sequences decreased Cx43 mRNA expression and progesterone production by luteal cells. The changes in Cx43 mRNA expression were positively correlated with changes in progesterone concentration in media. Thus, our data demonstrate a relationship between gap junctions and progesterone secretion that was supported by (1) the positive correlations between progesterone secretion and Cx43 mRNA expression and GJIC of luteal cells and (2) the inhibition of Cx43 mRNA expression by siRNA that resulted in decreased production of progesterone by luteal cells. This suggests that gap junctions may be involved in the regulation of steroidogenesis in the ovine corpus luteum.

Reproduction (2007) 133 641-651
\end{abstract}

\section{Introduction}

The mammalian corpus luteum $(\mathrm{CL})$ is a dynamic, transient endocrine gland and a major source of progesterone, which is critical for reproductive cyclicity and maintenance of pregnancy (Milvae et al. 1996, Pate 1996, Reynolds \& Redmer 1999, Niswender et al. 2000). In fact, inadequate luteal function has been shown to be one of the major causes of reproductive failure (Juengel \& Niswender 1999, Reynolds et al. 2002).

The corpus luteum is a complex, heterogeneous tissue composed of several cell types including steroidogenic (parenchymal) and nonsteroidogenic (nonparenchymal) cells (Milvae et al. 1996, Pate 1996). Cellular interactions mediated through contact-independent (humoral) and contact-dependent (gap junctional) pathways within the $\mathrm{CL}$ are believed to be essential for the maintenance of normal luteal tissue function (Redmer et al. 1991, Del Vecchio et al. 1994, 1995a, 1995b, Redmer \& Reynolds 1996, Grazul-Bilska et al. 1997a, 1997b).

Gap junctional intracellular communication $(G J I C)$ is involved in numerous physiological processes, including endocrine and exocrine secretions, providing a functional integration and coordination of activity within various glands (Meda et al. 1993, Munari-Silem \& Rousset 1996, Serre-Beinier et al. 2002). By facilitating the transport of nutrients, ions, and regulatory molecules less than $1 \mathrm{kDa}$ between adjacent cells, gap junctions have been demonstrated to play a fundamental role in regulation and coordination of cellular and/or tissue functions, including those in luteal tissues (Grazul-Bilska et al. 1997a, 1997b, Sohl \& Willecke 2004). In fact, several connexins are expressed in endocrine glands, with Cx43 identified as the most widespread 'endocrine' connexin (Meda et al. 1993, Morand et al. 1996, Munari-Silem \& Rousset 1996, Grazul-Bilska et al. 1997a, Serre-Beinier et al. 2002). 
Functional and structural gap junctions present in luteal cells are regulated by systemic and local regulators of luteal tissue function, such as hormones, growth factors, cytokines and second messengers (Grazul-Bilska et al. 1997a, 1997b, 2001). For several species, it has been demonstrated that luteinizing hormone (LH) and dbcAMP increase the rate of GJIC between luteal cells and progesterone secretion (Redmer et al. 1991, Grazul-Bilska et al. 1997a, 1997b). Moreover, Cx43 seems to be the major connexin within luteal tissues that is expressed in the $C L$ during the estrous cycle. Cx43 is localized to the luteal cell borders, therefore, $\mathrm{Cx} 43$ likely forms gap junctional channels allowing for GIIC (Grazul-Bilska et al. 1997a, 1997b).

Previously, we have demonstrated an association between progesterone secretion and GIIC (Grazul-Bilska et al. 1998a, 2001). To further investigate this relationship between progesterone secretion and gap junction function, we hypothesized that cell-cell contact would affect basal and/or induced progesterone secretion and that inhibition of $\mathrm{Cx} 43$ using siRNA would decrease progesterone secretion by luteal cells during the estrous cycle. Therefore, the objectives of this in vitro experiment were to: (1) determine the effects of cell-cell contact on basal and $\mathrm{LH}$ - or dbcAMP-induced progesterone secretion, Cx43 expression, and GJIC of luteal cells and (2) evaluate the effects of Cx43 siRNA on progesterone secretion and $\mathrm{Cx} 43 \mathrm{mRNA}$ expression in luteal cells collected throughout the estrous cycle in sheep. We used a cell density culture model, which creates a possibility of formation of more (confluent cultures) or less (sub-confluent cultures) gap junctional channels among cells.

\section{Materials and Methods}

\section{Animal treatment and tissue collection}

The protocols and animal care for this study were approved by the Institutional Animal Care and Use Committee at North Dakota State University. Crossbred ewes that exhibited at least one estrous cycle of normal duration (15-17 days) were treated twice daily (morning and evening) with i.m. injections of follicle stimulating hormone on days 13,14 , and 15 of the estrous cycle according to the protocols used previously (Grazul-Bilska et al. 2001). Day 0 of the estrous cycle (standing estrus) was determined using vasectomized rams.

\section{Luteal tissue dispersion and cell separation}

In Experiment 1, ovaries were collected from superovulated ewes, on days 5, 10, and 15 ( $n=5$ ewes/day) of the estrous cycle, and in Experiment 2, ovaries were collected on day $5(n=4)$ and day $10(n=4)$ of the estrous cycle. Superovulation was necessary to collect multiple $C L$ from each ewe for all analyses. McClellan et al. (1975) and Hild-Petito et al. (1987) demonstrated that $\mathrm{CL}$ from superovulated and non-superovulated ewes are comparable in hormonal production and cellular composition. Corpora lutea ( $n=4-34$ from each ewe; average $16.5 \pm 1.8$ (ewe) were dissected from the ovaries, and luteal tissue was separated from the connective tissue and cut into small pieces. Luteal tissue was dispersed using Hanks' Balanced Salt Solution (HBSS; Sigma) containing collagenase type $4(0.2 \% \mathrm{wt} / \mathrm{vol}$; Worthington, Biomedical Corporation, Lakewood, NJ, USA), BSA (2\% (wt/vol); Sigma), and antibiotics (100 U penicillin and $100 \mu \mathrm{g}$ streptomycin/ml; Gibco, Grand Island, NY, USA) as described previously (Grazul-Bilska et al. 2001). Dispersed luteal cells were resuspended in Dulbecco's modified Eagle plating medium (DMEM) containing 1\% fetal bovine serum (FBS; v/v; Gibco), 1\% calf serum (CS; v/v; Gibco), and antibiotics (100 U penicillin and $100 \mu \mathrm{g}$ streptomycin/ml; Gibco).

\section{Culture of luteal cells}

\section{Experiment 1}

Cells were counted by using a hemocytometer, and plated at concentrations of $50 \times 10^{3}, 100 \times 10^{3}, 300 \times$ $10^{3}$, and $600 \times 10^{3}$ steroidogenic cells on $35 \mathrm{~mm}$ petri dishes (10-12 dishes for each density and treatment for each ewe) in DMEM with $1 \%$ FBS, $1 \%$ CS, and penicillin/streptomycin for overnight preincubation at $37^{\circ} \mathrm{C}$ in a humidified atmosphere $\left(5 \% \mathrm{CO}_{2}: 95 \%\right.$ air) to facilitate cell attachment. Then, plating medium was changed to serum-free medium (Redmer et al. 1991), without (control), or with LH (100 ng/ml; United States Department of Agriculture bovine LHb5; Animal Hormone Program and the National Hormone and Pituitary Program, Beltsville, MD, USA) or dibutyryl cyclic adenosine $3^{\prime}, 5^{\prime}$-monophosphate (dbcAMP, 1 mM; analog of cyclic AMP; Sigma). The dose of LH or dbcAMP was chosen on the basis of previous experiments (Grazul-Bilska et al. 1996a, 2001). After 24 h incubation with treatments, GIIC of luteal cells was evaluated, medium was collected for progesterone determination, and cells were collected, resuspended in Trizol (Molecular Research Center, Cincinnati, OH, USA) and then stored at $-70^{\circ} \mathrm{C}$ until RNA was extracted. In addition, two sets of dishes from each culture were fixed for immunocytochemical detection of $\mathrm{Cx} 43$ protein and histochemical detection of $3 \beta$-hydroxysteroid dehydrogenase $(3 \beta-\mathrm{HSD})$. Pictures were taken from $3 \beta-\mathrm{HSD}$ stained cultures in order to determine a proportion of cells in contact with other cell(s).

\section{Experiment 2}

Dispersed luteal cells were plated in eight-chamber slides (50 000 cells/chamber) as described for Experiment 1. After overnight preincubation of luteal cells as described above, but before transfection, cells were washed three 
times with Opti-minimum essential medium (MEM) (Gibco) with 2\% serum without antibiotics.

\section{Analysis of contact-dependent GIJC}

\section{Experiment 1}

Evaluation of GIJC was conducted using a dye-coupling fluorescence recovery after photobleaching (FRAP) technique, and interactive laser cytometry (Redmer et al. 1991, Grazul-Bilska et al. 1996a, 2001). Briefly, after incubation with treatments, medium was replaced with fresh serum-free medium containing the fluorescent probe, calcein-AM (10 $\mu \mathrm{M}$; Molecular Probes; Eugene, OR, USA) and incubated for $10 \mathrm{~min}$ at $24{ }^{\circ} \mathrm{C}$. Then, dishes were washed with serum-free medium in order to remove the excess of calcein and were placed onto the interactive laser cytometer. Three fields $(180 \times 180 \mu \mathrm{m} /$ field) on each dish were identified for scanning, 6-12 cells were selected within each field and analyzed for initial fluorescence intensities. The fluorescent probe was photobleached in four to eight selected cells in each field. After photobleaching, the fluorescence intensity of all selected cells was quantified after 4 and $8 \mathrm{~min}$ in order to determine the rate of FRAP and only the linear portion of the fluorescence recovery curve was chosen for the evaluations (the first 4 min after photobleaching; Redmer et al. 1991, Grazul-Bilska et al. 2001).

\section{Imunohistochemistry}

\section{Experiment 1}

The presence of $\mathrm{Cx} 43$ in luteal cell cultures was visualized using the immunohistochemical method described previously (Grazul-Bilska et al. 2001). Briefly, luteal cells were fixed in ethanol:glacial acetic acid (5.7:1) for $20 \mathrm{~min}$ and rinsed several times in PBS containing Triton X-100 $(0.3 \%(\mathrm{v} / \mathrm{v}))$. Fixed cells were treated for 20 min with blocking buffer consisting of PBS (0.01 M phosphate and $0.14 \mathrm{M} \mathrm{NaCl}(\mathrm{pH} 7.3)$ ) containing $0.3 \%(\mathrm{v} / \mathrm{v})$ Triton $\mathrm{X}-100$ and $1 \%(\mathrm{v} / \mathrm{v})$ normal goat serum, and then incubated overnight at $4{ }^{\circ} \mathrm{C}$ with a rabbit polyclonal antibody against Cx43 (Zymed Laboratories Inc., San Francisco, CA, USA). This antibody has been demonstrated to be specific for ovine Cx43 (Grazul-Bilska et al. 1998b). Detection of the primary antibody was accomplished using fluorescein isothiocyanate-conjugated secondary antibody (i.e., goat anti-rabbit IgG; Zymed Laboratories Inc.). Controls were incubated with normal rabbit serum instead of primary antibody.

\section{Identification of steroidogenic cells}

\section{Experiment 1}

To detect $3 \beta$-HSD (marker of steroidogenic cells), cultured cells were fixed in $10 \%$ formalin for $10 \mathrm{~min}$ followed by rinsing with distilled water and incubated with staining solution containing BSA $(2 \mathrm{~g} / \mathrm{l})$, etiocholan$3 \beta$-ol-17-one (58 mg/l; Sigma), nitroblue tetrazolium (204 mg/l; Sigma), and $\beta$-nicotinamide adenine dinucleotide (996 mg/l; Sigma) in PBS (0.01 phosphate, 0.14 $\mathrm{NaCl}, \mathrm{pH} 7.3$ ) overnight at $4{ }^{\circ} \mathrm{C}$ (Grazul-Bilska et al. 1996a). Staining solution without steroid was used for controls. Then, after rinsing with PBS, the stained area was covered with a coverslip and mounted with aqueous mounting medium (Gel-mount; Biomeda, Foster City, CA, USA). Steroidogenic luteal cells containing $3 \beta-H S D$ exhibited dark staining.

\section{Image analysis}

\section{Experiment 1}

In order to determine the proportion of cells touching other cell(s) in each cell culture, ten randomly chosen fields from three dishes of each culture density, stained for the presence of $3 \beta-H S D$, were photographed. The total number of cells and the number of cells touching other cells per field was determined using an imageanalysis system (Image ProPlus, Media Cybernetics, Silver Spring, MD, USA). The data were reported as the percentage (mean \pm s.E.M.) of cells touching other cell(s) out of the total number of cells per field.

\section{Design of SiRNA for $\mathrm{Cx} 43$}

\section{Experiment 2}

Four targeted sequences (TS2, TS8, TS12, and TS24; Table 1), specific to $C_{x} 43$ gene, were designed as potential siRNA target sites following the instructions from Ambion (Austin, TX, USA). DNA oligos representing the antisense siRNA strands (complement of the target) and the sense strands of siRNA (same sequence as the target $\mathrm{mRNA}$ ) sequences were purchased from Dharmacon Research (Madison Inc, WI, USA; Table 1). For siRNA synthesis, sense and antisense strands of these siRNA templates were in vitro transcribed for $2 \mathrm{~h}$, using T7 RNA polymerase, in separate reactions. Then, reactions for each targeted sequence were combined, mixed, and

Table 1 Sequence of siRNA for targeted sequences (TS) specific to Cx43.

\begin{tabular}{lll}
\hline TS $^{\mathrm{a}}$ & \multicolumn{1}{c}{ siRNA } & \multicolumn{1}{c}{ Nucleotide sequence } \\
\hline 2 & Antisense & 5'-UCCUGCUACUGGGGACAGCtt-3 \\
& Sense & 5'-GCUGUCCCCAGUAGCAGGAtt-3' \\
8 & Antisense & 5'-UCUCUCAUGUGCGCUUCUGtt -3' \\
& Sense & 5'-CAGAAGCGCACAUGAGAGAtt -3' \\
12 & Antisense & 5'-CAAGAAAGAGGAGGAACUCtt -3' \\
& Sense & 5'-GAGUUCCUCCUCUUUCUUGtt-3' \\
24 & Antisense & 5'-GAGCACGGCAAGGUGAAGAtt-3' \\
& Sense & 5'-UCUUCACCUUGCCGUGCUCtt-3' \\
\end{tabular}

The antisense siRNA strand is the reverse complement of the target sequence, $\mathrm{Cx} 43$. The sense siRNA strand is the same sequence as the target mRNA sequence without the $5^{\prime}$ AA sequence.

aTS, targeted sequence. 
incubated to facilitate hybridization. After overnight incubation, double-stranded (ds) siRNA for each targeted sequence were purified and used following the Mirus (Madison, WI, USA) transfection protocol.

\section{Visualization of transfection}

\section{Experiment 2}

To determine the transfection efficiency of luteal cells, fluorescently (Cy3) labeled TS8 siRNA purchased from Dharmacon Research Inc. was used (Fig. 1).

\section{Transfection with siRNA}

\section{Experiment 2}

Luteal cells were cultured in $250 \mu$ l Opti-MEM/DMEM (1:4) medium/well with $2 \%$ serum without antibiotics containing: no supplements (control), transfection
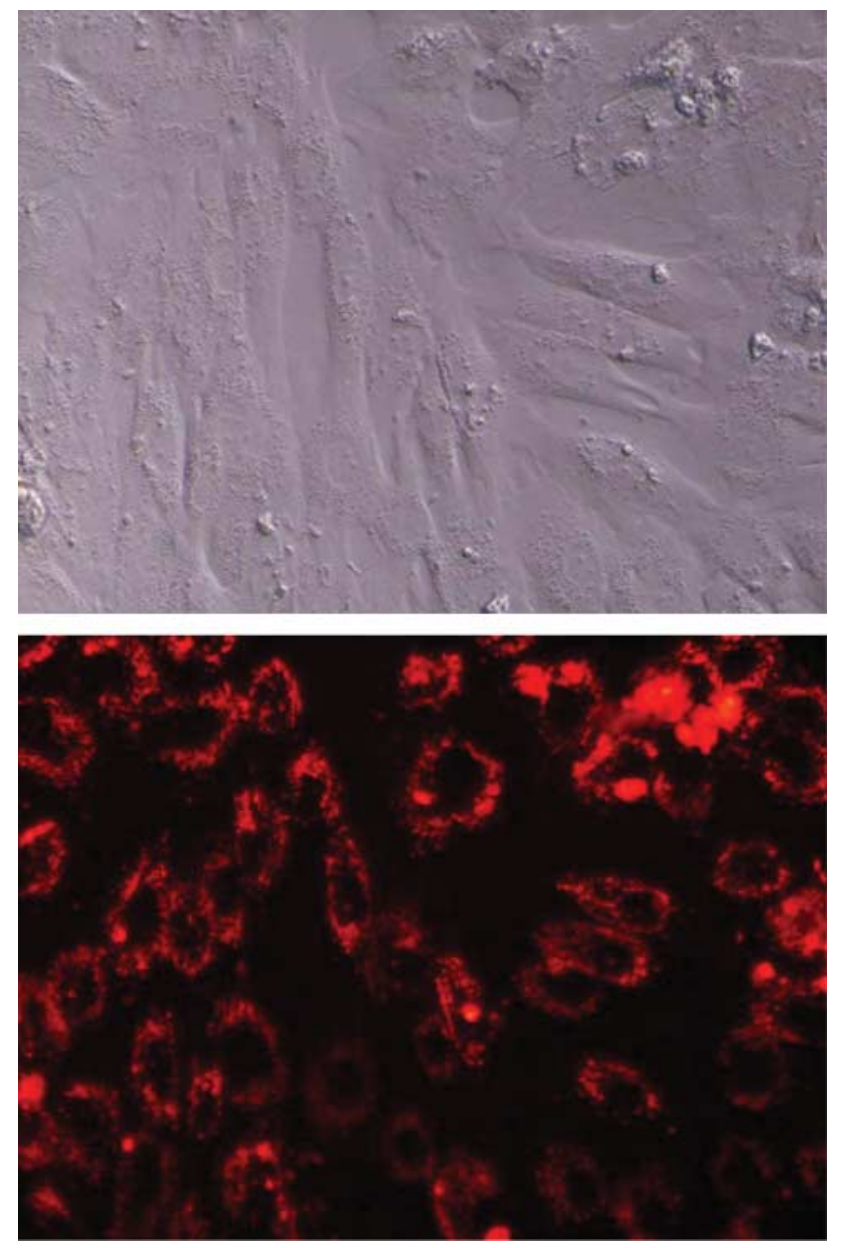

Figure 1 Representative micrographs of luteal cells transfected with 20 nM TS8 siRNA for Cx43 labeled with Cy3. Micrograph on the top is a light microscopic image of cultured luteal cells (differential interface contrast; Hoffman modulation) and on the bottom is a fluorescence microscopy image of the same area. Bright red fluorescence indicates transfected cells. Magnification $200 \times$. reagent (TransIT-TKO; Mirus) without siRNA, transfection reagent (TransIT-TKO; Mirus) with TS2, TS8, TS12 or TS24 (20 nM). After $24 \mathrm{~h}$ incubation with treatments, the morphology and viability of cells were evaluated, and then medium was collected for evaluation of progesterone concentration using RIA. The cells were collected and frozen for extraction of total cellular (tc) RNA for real-time PCR analysis.

\section{RNA isolation and RT}

Experiments 1 and 2

RNA was extracted from cultured cells using Trizol (Molecular Research Center) according to the manufacturer's recommendations. Polyacrylamide carrier solution was added to facilitate greater RNA yields. The Agilent 2100 Bioanalyzer (Agilent Technologies, Palo Alto, CA, USA) was used to determine the quantity and quality of total cellular RNA samples. All RNA samples were reverse transcribed in triplicate $20 \mu \mathrm{l}$ reactions using Taqman RT Reagents (Applied Biosystems, Foster City, CA, USA). All cDNAs from the RT reaction were stored at $-20{ }^{\circ} \mathrm{C}$ prior to PCR analysis (Borowczyk et al. 2006a).

\section{Real-time quantitative RT-PCR}

\section{Experiments 1 and 2}

Cx43 mRNA expression was determined by quantitative real-time RT-PCR analysis using the ABI PRISM 7000 Sequence Detection System and software. Primers and probes were designed using the Primer Express software version 2.0 and CDNA from ovine heart was used as a standard curve (Borowczyk et al. 2006a). For an RNA control, 18S rRNA was analyzed using the same PCR protocols and the human 18S PDAR kit from Applied Biosystem. Then, Cx43 mRNA values were normalized to $18 \mathrm{~S}$ rRNA by dividing them by their corresponding 18S rRNA values (Borowczyk et al. 2006a).

\section{Progesterone RIA}

\section{Experiments 1 and 2}

Concentrations of progesterone in culture media were measured according to the protocol used previously (Grazul-Bilska et al. 1996a, 2001). The sensitivity of the assay was $12.5 \mathrm{pg} /$ tube and the intra- and interassay coefficients of variation were 4.5 and $8.9 \%$, and 4.8 and $8.5 \%$, for experiments 1 and 2 respectively.

\section{Statistical analysis}

Data for progesterone secretion by luteal cells, Cx43 mRNA expression and GIJC of luteal cells, and the 
proportion of cells in contact with other cell(s) were analyzed using general lineal model ANOVA (SAS 2005). When an $F$-test was significant $(P<0.05)$, differences between means were evaluated with least square means procedure (Kirk 1982). Correlations between the progesterone concentration in medium, Cx43 expression and GJIC were evaluated using PROC CORR of SAS.

\section{Results}

In Experiment 1, the proportion of cells touching other cell(s) within each cell density culture was similar throughout the estrous cycle, therefore the data were combined (see below) for days 5, 10, and 15 of the estrous cycle. The greatest $(P<0.01)$ proportion of cells touching one or more cells was detected in cultures with $600 \times 10^{3}$ cells/dish, and gradually decreased $(P<0.01)$ in cultures with $300 \times 10^{3}, 100 \times 10^{3}$, and $50 \times$ $10^{3} \mathrm{cells} /$ dish $(98.5 \pm 1,83.24 \pm 1.2,73.3 \pm 1.4,51 \pm$ $1.7 \%$ respectively) across the days of the estrous cycle or treatment.

Across all cell densities, basal progesterone secretion by luteal cells was greater $(P<0.001)$ on day 10 than on days 5 or 15 of the estrous cycle ( $414 \pm 100$ vs $198 \pm 52$ and $164 \pm 43 \mathrm{ng} / \mathrm{ml}$ respectively). As expected, basal progesterone concentration in media was the lowest $(P<$ $0.001)$ in cultures with densities of 50 or $100 \times 10^{3}$ cells/dish $(54 \pm 10$ or $104 \pm 21 \mathrm{ng} / \mathrm{ml})$, greater $(P<$ $0.001)$ in cultures with $300 \times 10^{3}$ cells/dish $(282 \pm$ $54 \mathrm{ng} / \mathrm{ml})$ and the greatest $(P<0.001)$ in cultures with $600 \times 10^{3}$ cells/dish $(594 \pm 117 \mathrm{ng} / \mathrm{ml})$ across the estrous cycle. When basal progesterone secretion was expressed per cell (progesterone concentration in $1 \mathrm{ml}$ medium divided by cell number), progesterone levels were similar in cultures having a different cell density/dish when compared within the same day of the estrous cycle (Table 2). However, basal progesterone secretion expressed per cell was affected $(P<0.05)$ by the day of the estrous cycle (Table 2). Luteal cells from day 10 of the estrous cycle secreted more $(P<0.05)$ progesterone than cells from days 5 and 15 of the estrous cycle at cell densities $50 \times 10^{3}$ and $600 \times 10^{3}$ cells/dish (Table 2). However, for cell densities $100 \times 10^{3}$ and $300 \times 10^{3}$ cells/dish, progesterone secretion by luteal cells from day 10 was similar to that on day 5 but greater $(P<0.05)$ than that on day 15 of the estrous cycle (Table 2$)$.

Overall, LH and dbcAMP increased $(P<0.001)$ progesterone secretion by luteal cells in cultures with a different cell density from days 5, 10, and 15 of the estrous cycle. Since we did not observe the effects of cell density on LH- or dbcAMP-induced progesterone secretion expressed per cell, data for all cell densities are combined within a day of the estrous cycle (Fig. 2). $\mathrm{LH}$ increased $(P<0.01)$ progesterone secretion on day 5 and tended to increase progesterone secretion $(P<0.1)$ on days 10 and 15 of the estrous cycle. However, dbcAMP increased $(P<0.01)$ the progesterone secretion by luteal cells across all days of the estrous cycle (Fig. 2).

Across all treatments and cell densities, basal $\mathrm{C} \times 43$ mRNA expression by luteal cells was greater $(P<0.001)$ on day 10 than on days 5 and 15 of the estrous cycle $(0.53 \pm 0.07$ vs $0.29 \pm 0.04$ or $0.33 \pm 0.03$ relative expression respectively). Basal Cx43 mRNA expression was affected $(P<0.001)$ by days of the estrous cycle and by cell density (Table 3 ). On days 5 and 10 of the estrous cycle, Cx43 mRNA expression by luteal cells was greater $(P<0.05)$, but on day 15 tended $(P<0.1)$ to be greater, in higher cell density cultures $\left(300 \times 10^{3}\right.$ or $600 \times 10^{3}$ cells/ dish) than in lower cell density cultures $\left(50 \times 10^{3}\right.$ or $100 \times 10^{3}$ cells/dish; Table 3).

Overall, LH and dbcAMP increased $(P<0.001) \mathrm{Cx} 43$ mRNA expression in luteal cells from cultures with a different cell density from different days of the estrous cycle. Since the effects of $\mathrm{LH}$ or dbcAMP on Cx43 mRNA expression were similar at all cell density cultures, data are combined for all cell densities within a day of the estrous cycle (Fig. 3). LH increased $(P<0.05)$ Cx43 mRNA expression on days 5 and 10 , and dbcAMP increased $(P<0.03)$ and tended $(P<0.1)$ to increase Cx43 mRNA expression on days 5 and 10 respectively (Fig. 3). Cx43 mRNA expression by luteal cells from day 15 of the estrous cycle was not affected by $\mathrm{LH}$ or dbcAMP treatment (Fig. 3).

Across all treatments and days of the estrous cycle, the rate of GIIC was the greatest $(P<0.001)$ in cultures with $600 \times 10^{3}$ cells/dish $(1.7 \pm 0.03 \% / \mathrm{min})$, lower in cultures with $300 \times 10^{3}$ cells/dish $(1.5 \pm 0.03 \% / \mathrm{min})$, and $100 \times$ $10^{3}$ cells $/$ dish $(1.0 \pm 0.02 \% / \mathrm{min})$, and least in cultures with $50 \times 10^{3}$ cells/dish $(0.9 \pm 0.02 \% / \mathrm{min})$. LH increased $(P<0.05)$ the rate of GJIC of luteal cells in cultures with

Table 2 Basal progesterone concentration in medium (expressed as pg/cell based on progesterone concentration in $1 \mathrm{ml}$ medium) from different cell density cultures $\left(50-600 \times 10^{3}\right.$ cells/dish) on days 5, 10, and 15 of the estrous cycle.

\begin{tabular}{lccc}
\hline & \multicolumn{3}{c}{ Cell density } \\
\cline { 2 - 4 } Day of the estrous cycle & $50 \times 10^{3}$ & $100 \times 10^{3}$ & $300 \times 10^{3}$ \\
\hline 5 & $0.7 \pm 0.2^{*}$ & $1.0 \pm 0.3^{*}$ & $0.8 \pm 0.2^{*+}$ \\
10 & $2.0 \pm 0.3^{+}$ & $1.7 \pm 0.4^{*}$ & $1.6 \pm 0.4^{*}$ \\
15 & $0.5 \pm 0.1^{*}$ & $0.4 \pm 0.1^{+}$ & $0.5 \pm 0.1^{+}$ \\
\hline
\end{tabular}

Values are expressed as mean \pm S.E.M. Individual basal values were obtained from each cell culture density without LH or dbcAMP-treatments.

${ }^{*}+{ }^{+} P<0.05$, within a column means with different superscripts differ. 


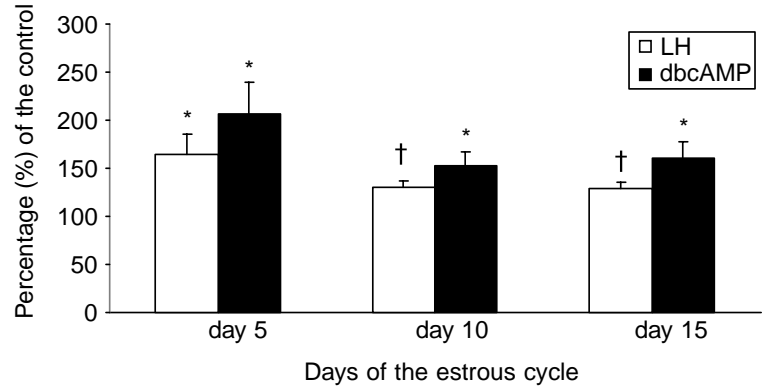

Figure 2 Effects of $\mathrm{LH}$ and dbcAMP on progesterone secretion by luteal cells from days 5, 10, and 15 of the estrous cycle. Data are presented as a percentage of the control (no treatment, 100\%). Data are combined for all cell density cultures within a day of the estrous cycle. For basal progesterone production (pg/cell) in control (no treatment) cultures, see Table 2. Mean \pm S.E.M. compared with control (no treatment; $100 \%$ ) differ; $* P<0.01$ and ${ }^{\dagger} P<0.1$.

densities of $300 \times 10^{3}$ and $600 \times 10^{3}$, but not in cultures with $50 \times 10^{3}$ or $100 \times 10^{3}$ cells/dish on days 5 and 10 of the estrous cycle (Fig. 4). DbcAMP increased $(P<0.05)$ the rate of GIIC of luteal cells in cultures with densities of $100 \times 10^{3}, 300 \times 10^{3}$, and $600 \times 10^{3}$, but not with $50 \times 10^{3}$ cells/dish on day 5 , and also in cultures with $300 \times 10^{3}$ and $600 \times 10^{3}$, but not for cultures with $50 \times 10^{3}$ or $100 \times 10^{3}$ cells/dish on day 10 of the estrous cycle (Fig. 4). However, on day 15 of the estrous cycle, LH or dbcAMP did not affect the rate of the GJIC in any cell-density culture (Fig. 4). Across all cultures, there were no treatment or day of the estrous cycle effects on the rate of GIIC for cells, which were not photobleached (positive control, $n=821$ ) or for cells, which were photobleached but not in contact with other cells (negative control, $n=350$ ).

Overall, the progesterone secretion was positively correlated with Cx43 mRNA expression, and Cx43 mRNA expression was positively correlated with the rates of GJIC (Table 4). Moreover, changes in progesterone secretion caused by the day of the estrous cycle and the treatments were positively correlated with changes in Cx43 mRNA expression and GJIC of luteal cells throughout the estrous cycle $(R=0.209$ and 0.257 , $P<0.006$ respectively).

$\mathrm{Cx} 43$ protein was found on luteal cell borders (Fig. 5A and $\mathrm{B})$, and most luteal cells in every culture expressed $3 \beta$-HSD (Fig. 6A-D).
In Experiment 2, TS8 and 24, but not TS2 or 12, affected $(P<0.05)$ progesterone secretion and $\mathrm{C} \times 43$ mRNA expression by luteal cells from days 5 or 10 of the estrous cycle (Fig. 7). Since similar results were obtained for both the days, the data for days 5 and 10 were combined. Progesterone secretion and $\mathrm{C} \times 43$ mRNA expression were decreased $(P<0.02)$ by approximately 30 and $40 \%$ respectively, in the presence of siRNA for Cx43 in luteal cell cultures. These changes in $\mathrm{Cx} 43$ mRNA expression were positively correlated $(P<0.01)$ with changes in progesterone concentration in media $(R=0.543)$.

\section{Discussion}

The present study clearly shows an association between the major function of luteal cells, which is the secretion of progesterone, and gap junction function, since a positive correlation was demonstrated between progesterone secretion, Cx43 mRNA expression, and GJIC by luteal cells. In addition, progesterone secretion, $\mathrm{Cx} 43$ mRNA expression, and the rate of GIIC were affected by the day of the estrous cycle, cell density and/or treatment with LH and/or dbcAMP. Although it has been previously suggested that gap junctions are involved in ovarian steroidogenesis (Grazul-Bilska et al. 1998a, 2001, 2002), this is the first report showing a positive correlation between progesterone production, $\mathrm{Cx} 43$ mRNA expression, and the rate of GIIC of ovine luteal cells from several stages of the estrous cycle. Furthermore, we demonstrated that inhibition of Cx43 mRNA expression by $\mathrm{Cx} 43$ siRNA decreased the production of progesterone by luteal cells. This observation suggests that gap junctional $\mathrm{Cx} 43$ is involved in the regulation of progesterone production by luteal cells in sheep.

Primary cultures of endocrine cells have been used to investigate the role of gap junctions in regulation of cellular function in numerous studies (Oyoyo et al. 1997, Grazul-Bilska et al. 1998a, Meda 2000, Shah \& Murray 2001). In addition, cell density has been previously shown to influence the ability of cells to respond to applied treatments (Pate et al. 1987, Larson et al. 1997). Most cells in our cultures expressed steroidogenic activity, as demonstrated by $3 \beta$-HSD staining, and

Table 3 Basal Cx43 mRNA expression in luteal cells from different cell density cultures (50-600 $\times 10^{3}$ cells/dish) on days 5, 10, and 15 of the estrous cycle.

\begin{tabular}{|c|c|c|c|c|}
\hline \multirow[b]{2}{*}{ Day of the estrous cycle } & \multicolumn{4}{|c|}{ Cell density } \\
\hline & $50 \times 10^{3}$ & $100 \times 10^{3}$ & $300 \times 10^{3}$ & $600 \times 10^{3}$ \\
\hline 5 & $0.2 \pm 0.04^{*}$ & $0.2 \pm 0.04^{*}$ & $0.3 \pm 0.1^{*^{+\neq}}$ & $0.4 \pm 0.1^{t \neq}$ \\
\hline 10 & $0.2 \pm 0.01 *$ & $0.3 \pm 0.04^{*}$ & $0.7 \pm 0.1^{1 \S}$ & $0.9 \pm 0.1^{+\S}$ \\
\hline 15 & $0.2 \pm 0.02 *$ & $0.2 \pm 0.04 *$ & $0.4 \pm 0.1^{+\ddagger}$ & $0.4 \pm 0.1^{\dagger \neq}$ \\
\hline
\end{tabular}

Values are expressed as mean \pm s.E.M. Individual basal values were obtained from each cell culture density without LH or dbcAMP-treatments.

${ }^{*}, \mathrm{t}$ Within a row, means with different superscripts differ; $P<0.05$ for days 5 and 10 , and $P<0.1$ for day 15 of the estrous cycle. ${ }^{\neq, \S}$ Within a column, means with different superscripts differ $(P<0.001)$. 


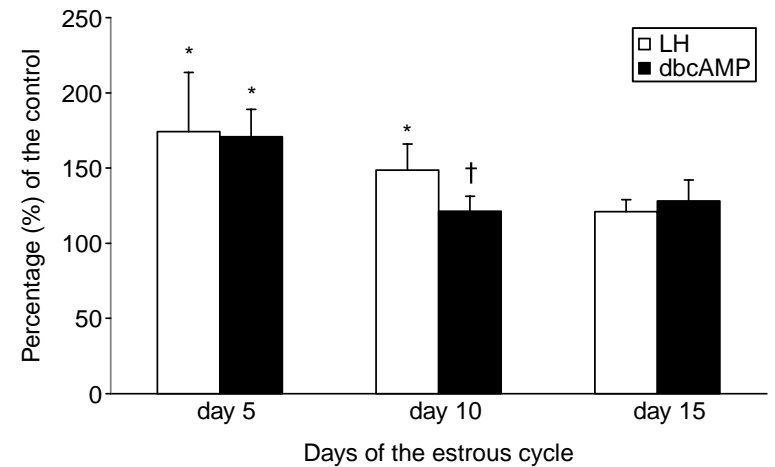

Figure 3 Effects of $\mathrm{LH}$ and dbcAMP on Cx43 mRNA expression in luteal cells from days 5, 10, and 15 of the estrous cycle. Data are presented as a percentage of the control (no treatment, 100\%). For basal Cx43 mRNA expression in control (no treatment) cultures, see Table 3. Data are combined for all cell densities within a day of the estrous cycle. Mean \pm S.E.M. compared with control (no treatment; 100\%) differ; ${ }^{*} P<0.03$ and ${ }^{\dagger} P<0.1$.

expressed Cx43 on luteal cell borders, which indicated the presence of functional gap junctional channels.

The positive correlation between progesterone secretion and Cx43 mRNA expression, and between Cx43 mRNA expression and GJIC of luteal cells demonstrated in the present study indicates that structural and functional gap junctions are involved in the regulation of luteal steroidogenesis, and further implies that $\mathrm{C} \times 43$ is involved in the regulation of progesterone secretion. The decreased progesterone secretion by ovine luteal cells with siRNA-suppressed Cx43 mRNA expression confirms this observation. Furthermore, it has been demonstrated that $\mathrm{Cx} 43$ is involved in the regulation of the secretory function of adrenal cells (Oyoyo et al. 1997), and that structural and functional channels formed by $\mathrm{Cx} 43$ are essential in the steroidogenic processes of bovine adrenal tissue (Shah \& Murray 2001). In addition, a positive correlation between increased $\mathrm{Cx} 43$ protein expression and enhanced insulin secretion by B-cells of the pancreas was demonstrated recently in in vivo and in vitro

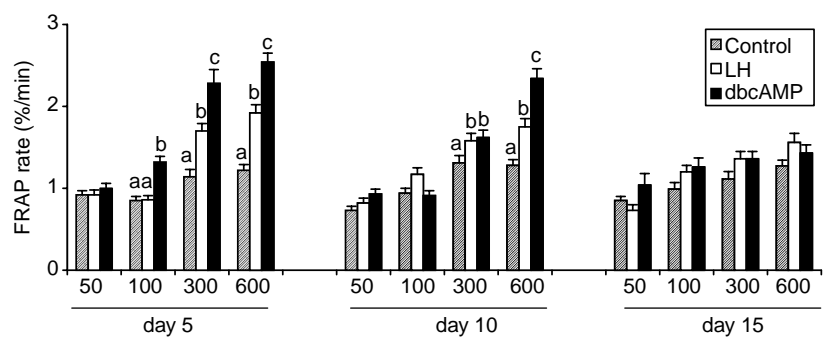

Days of the estrous cycle

Figure 4 Effects of $\mathrm{LH}$ and dbcAMP on the rate of GJIC of luteal cells in cultures with 50,100,300, and $600 \times 10^{3}$ cells/dish from days 5, 10, and 15 of the estrous cycle. Number of cells for each density and treatment ranged from 48 to 155 . Within a day of the estrous cycle and cell culture density, mean \pm S.E.M. compared with control (no treatment; $100 \%$ ) differ; ${ }^{\text {a,b,c }} P<0.05$.
Table 4 Correlation coefficient $(r)$ between progesterone (P4) concentration in medium (expressed as $\mathrm{ng} / \mathrm{ml}$ and as $\mathrm{pg} /$ cell based on progesterone concentration in $1 \mathrm{ml}$ medium), Cx43 mRNA expression and GJIC in luteal cells.

\begin{tabular}{lllll}
\hline Overall & \multicolumn{1}{c}{$\mathbf{P 4} \mathrm{ng} / \mathrm{ml}$} & \multicolumn{1}{c}{ P4 pg/cell } & Cx43 mRNA & \multicolumn{1}{c}{ GJIC } \\
\hline P4 ng/ml & - & 0.544 & 0.601 & 0.480 \\
& & $P<0.001$ & $P<0.001$ & $P<0.001$ \\
P4 pg/cell & 0.544 & - & 0.220 & 0.055 \\
& $P<0.001$ & & $P<0.003$ & $P<0.5$ \\
Cx43 mRNA & 0.601 & 0.220 & - & 0.532 \\
& $P<0.001$ & $P<0.003$ & & $P<0.001$ \\
\hline
\end{tabular}

evaluations (Collares-Buzato et al. 2001, Leite et al. 2005). Therefore, the above observations demonstrate that both $\mathrm{Cx} 43$ and GIIC are involved in the regulation of hormone production in several endocrine glands including the $\mathrm{CL}$.

In the present study, basal progesterone secretion was the greatest in the mid-luteal stage when the $\mathrm{CL}$ is completely differentiated, represented by day 10 of the estrous cycle. This observation agrees with previously published results showing a similar pattern of
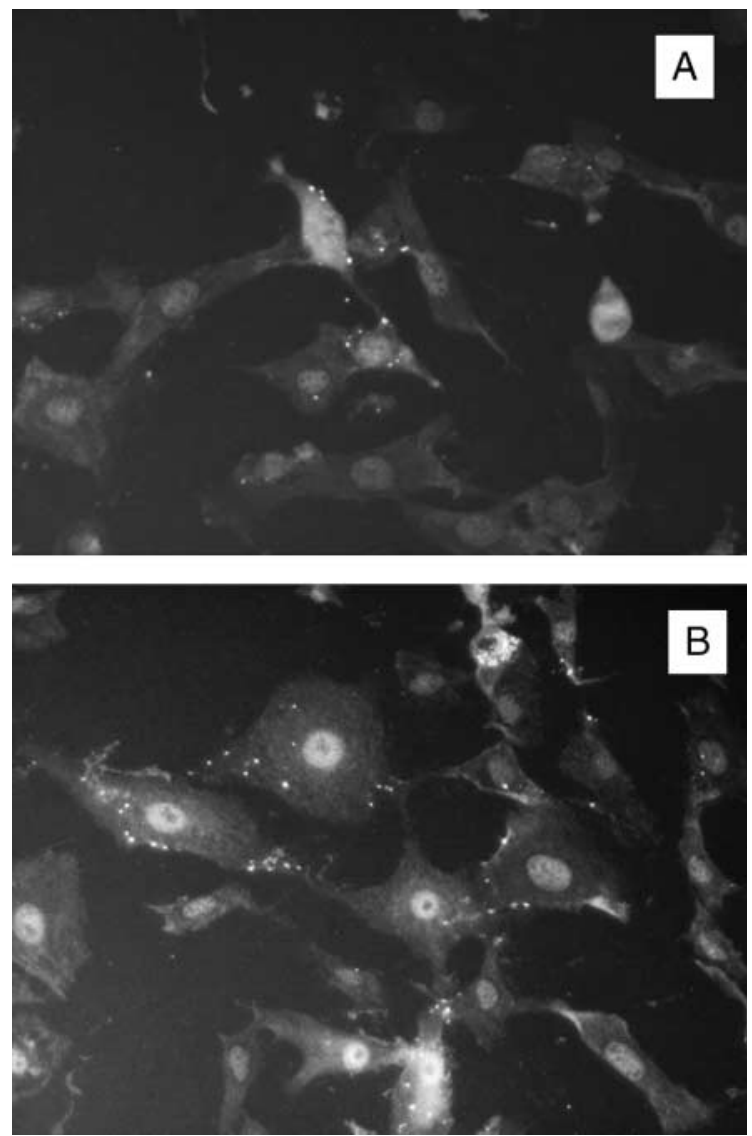

Figure 5 Representative micrographs of positive Cx43 staining in cultures with $50 \times 10^{3}(\mathrm{~A})$ and $300 \times 10^{3}$ (B) luteal cell/dish from day 5 of the estrous cycle. The morphology and staining pattern in cells with other densities and cells from days 10 and 15 of the estrous cycle were similar (data not shown). Control sections did not exhibit positive $\mathrm{C} \times 43$ staining (not shown). Magnification $400 \times$. 


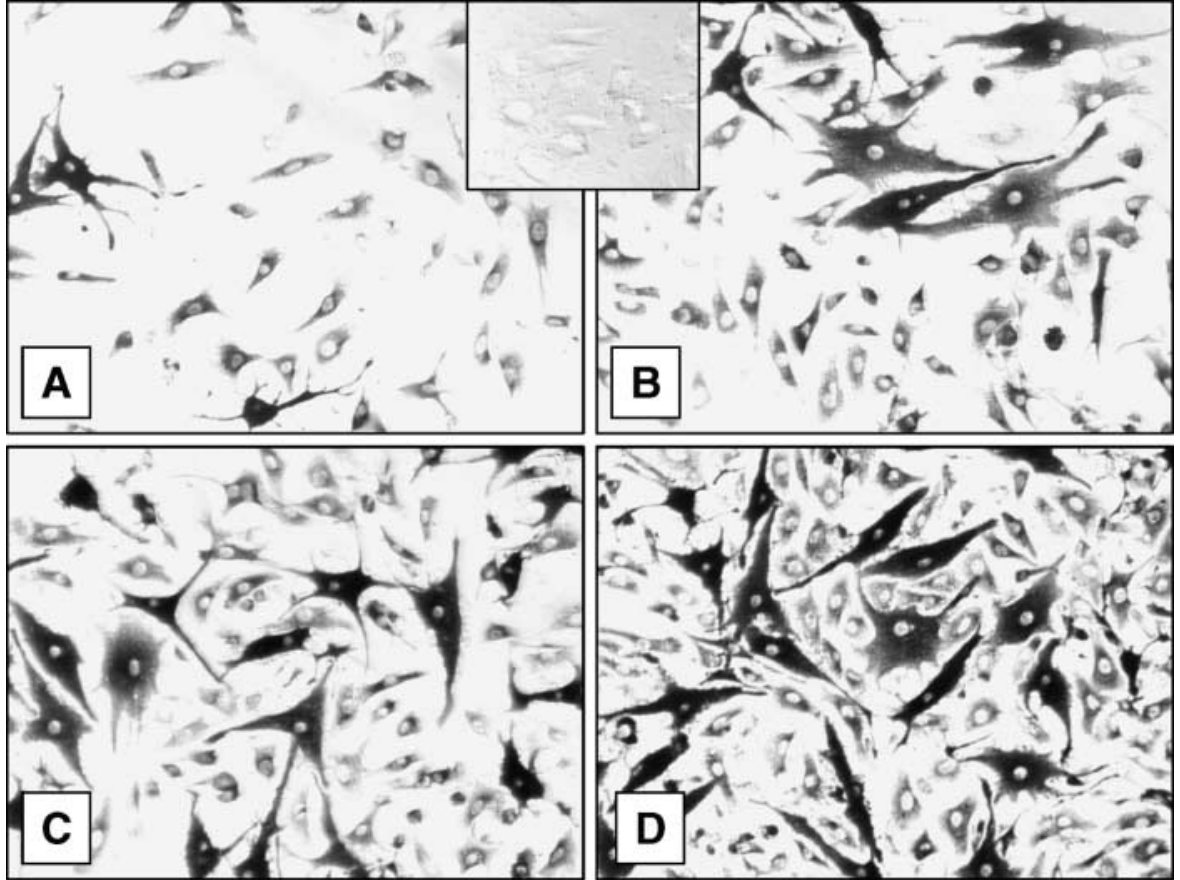

Figure 6 Representative micrographs of $3 \beta$-HSD staining in cultures with $50 \times 10^{3}$ (A), $100 \times 10^{3}$ (B), $300 \times 10^{3}(\mathrm{C})$, and $600 \times 10^{3}$ (B) luteal cell/dish from day 5 of the estrous cycle. Staining of luteal cells from days 10 and 15 was similar to day 5 of the estrous cycle. Insert in A-B demonstrates a lack of steroidogenic activity in control staining. Magnification $200 \times$. progesterone secretion in vitro and in vivo in sheep (Jablonka-Shariff et al. 1993, Grazul-Bilska et al. 1996b, 2001). We have also demonstrated that LH has greater stimulatory effects on progesterone production at the earlier rather than later stages of luteal development (day 5 versus days 10 and 15 of the estrous cycle). In addition, dbcAMP treatment increased progesterone production across all days of the estrous cycle. Responsiveness to $\mathrm{LH}$ and dbcAMP demonstrates that cells used in this study were functional. These stimulatory effects of $\mathrm{LH}$ and/or dbcAMP on progesterone production by luteal cells have also been demonstrated previously in sheep (Niswender \& Nett 1994, Grazul- Bilska et al. 1995, 2001, Niswender et al. 2000).

Since it has been hypothesized that cellular interactions are involved in the regulation of progesterone secretion, several studies have been performed to determine the effects of cell-cell contact on progesterone secretion by luteal cells, but contradictory results have been reported. Pate et al. (1987) demonstrated that basal progesterone production and/or utilization of low- or high-density lipoproteins by bovine luteal cells, was not affected by cell density, while $\mathrm{LH}$-induced progesterone production was greater in low-density cultures when compared with mediumor high-density cultures during short-term treatment. Alternatively, it has been demonstrated that bovine luteal cells without contact secreted less basal and LH-induced progesterone than those with established cellular contacts, and cellular contacts were required for maximal stimulation of progesterone synthesis by $\mathrm{LH}$
(Del Vecchio et al. 1995a, 1995b). However, in our study, cell density did not affect LH or dbcAMP-induced progesterone secretion when evaluated on a per cell basis and the reason for discrepancies between our results and others may be due to species-specific differences. Our data have shown that progesterone production by luteal cells depends on the stage of luteal development, and LH and dbcAMP effects. However, basal- and LH- or dbcAMP-stimulated progesterone secretions do not depend on cell-cell contact in vitro in this study.

This and previous studies have demonstrated that, in sheep, Cx43 protein and/or mRNA expression in the CL

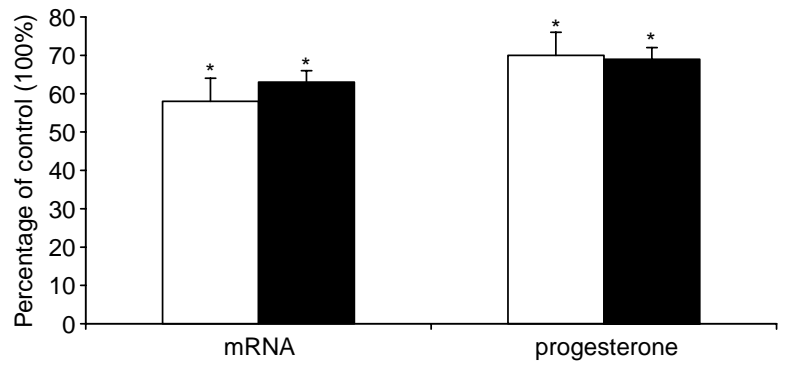

Figure 7 Effects of transfection of ovine luteal cells with Cx43 siRNA using targeted sequence (TS) 8 (open bars) and 24 (black bars) on Cx43 mRNA expression and progesterone production in vitro. Data are presented as a percentage of the control (no treatment, 100\%) and expressed as mean \pm S.E.M. Since day of the estrous cycle did not have any effect, data are combined for days 5 and 10 . In control cultures, relative $\mathrm{Cx} 43 \mathrm{mRNA}$ expression was $0.7 \pm 0.1$ and progesterone concentration in medium was $270 \pm 42 \mathrm{ng} / \mathrm{ml}$. Mean \pm s.E.M. compared with control $(100 \%)$ differ; $* P<0.02$. 
were the highest during the early and mid-luteal stages of the estrous cycle, and that $\mathrm{Cx} 43$ protein was present on steroidogenic luteal cell borders (Grazul-Bilska et al. 1997a, 1997b, 1998b, 2001, Borowczyk et al. 2006a). In the present study, treatment with either LH or dbcAMP increased Cx43 mRNA expression during the early and mid-luteal stages of the estrous cycle. Also, GrazulBilska et al. (2000) reported that LH treatment increased Cx43 protein expression in ovine luteal tissues in vivo. In addition, Cx43 mRNA expression was the greatest in higher cell densities in this study. In greater cell density cultures, almost all cells remained in contact with other cells, and therefore multiple gap junctional channels were formed. These gap junctional channels are very likely formed by $\mathrm{C} \times 43$ since $\mathrm{Cx} 43$ protein was detected on luteal cell borders. This supports the previous observation that $\mathrm{Cx} 43$ is a major connexin in the luteal tissue. In agreement with our data, Rosenberg et al. (1996) demonstrated that Cx43 mRNA expression increased in parallel to cell density in two different rat hepatic cell lines. These results suggest that $\mathrm{Cx} 43$ may play a regulatory role in early and differentiated $\mathrm{CL}$, and is likely involved in the regulation of luteal function.

In the current study, luteal cells from all stages of the estrous cycle established GJIC, and both $\mathrm{LH}$ and dbcAMP increased GJIC at the early and mid-luteal stages in cultures with the highest cell densities. Similarly, GJIC in confluent luteal cell cultures was affected by hormonal treatments, for example $\mathrm{LH}$ and dbcAMP, and was greater at the early and mid-luteal than the late-luteal stage of the estrous cycle in cows and sheep (Redmer et al. 1991, Grazul-Bilska et al. 1996a, 1996b, 1997a, 1997b, 2001). Also, in several other cell types, CAMP has been shown as a potent stimulator of GJIC (Saez et al. 1993). Therefore, it seems that GJIC is important for signal transduction during luteal tissue growth, differentiation, and regression. Since, during the late luteal phase, $\mathrm{LH}$ and $\mathrm{dbcAMP}$ stimulated progesterone secretion, but not GJIC and Cx43 expression, it seems that regulation of these two processes is independent during luteal regression. However, gap junctions seem to be necessary for luteolytic process, since during $C L$ regression expression of $\mathrm{Cx} 43 \mathrm{mRNA}$ and protein, and GJIC are maintained at a relatively high level (this study; Grazul-Bilska et al. 1998b, Borowczyk et al. 2006a). In fact, it has been hypothesized that gap junctions facilitate transferring of luteolytic signal within luteal tissues (Niswender \& Nett 1994, Grazul-Bilska et al. 1997a, 1997b).

In the low cell density cultures, the rate of GJIC of luteal cells and Cx43 mRNA expression were less than in the high cell density cultures, but these cells produced similar levels of progesterone. In addition, LH and dbcAMP stimulated progesterone and Cx43 mRNA expression in all cell density cultures, and stimulated GJIC in the greater cell density but not lower cell density cultures. In the low cell density cultures, fewer gap junctional channels were formed on luteal cell borders, as observed by immunolocalization of $\mathrm{Cx} 43$ proteins. Therefore, with fewer gap junctions present, the increase of dye transfer in $\mathrm{LH}$ or dbcAMP-stimulated luteal cells in the lower cell density cultures could not be detected because the FRAP technique was not sensitive enough to detect this low level of dye transfer.

$\mathrm{CL}$ function is regulated by several factors including $\mathrm{LH}$, which may activate second messengers including cAMP, protein kinases (PKC or PKA), or calcium, and LH has stimulatory effect on progesterone synthesis (Leung \& Steele 1992, Grazul-Bilska et al. 1997b, 2001, Niswender et al. 2000, Davis \& Rueda 2002). It has been clearly demonstrated that LH stimulates progesterone secretion by increasing CAMP concentration in luteal cells (Milvae et al. 1996). In addition, cAMP has been shown to stimulate progesterone production by luteal cells in several species (Leung \& Steele 1992). Also, our study confirmed the previous observation that $\mathrm{LH}$ and/or dbcAMP have a stimulatory effect on progesterone production and on the rate of GJIC between luteal cells (Grazul-Bilska et al. 1996a, 1996b, 1997a, 1997b). However, our study demonstrated that $\mathrm{LH}$ has an additional function in the $\mathrm{CL}$, which is the stimulation of Cx43 mRNA expression in ovine luteal cells.

Connexins are considered as proteins with the main function of forming gap junctional channels between adjacent cells (Goodenough et al. 1996, Kumar \& Gilula 1996, Yamasaki \& Naus 1996). However, this and other studies have demonstrated that connexins may play additional cellular functions independent of formation of gap junctional channels, including regulation of endocrine function (Meda et al. 1993, Munari-Silem \& Rousset 1996, Oyoyo et al. 1997, Wynn et al. 2002) and control of cell and/or tissue growth (Yamasaki \& Naus 1996, Naus 2002). Moreover, Moorby \& Patel (2001) demonstrated that Cx43 had a dual function in regulating cellular growth independently of gap junction formation. In fact, Moorby \& Patel (2001) have clearly shown that $\mathrm{Cx} 43$ acts directly on cell behavior in gap junction-independent mechanisms and has a unique role when compared with other connexins. In addition, gap junctional proteins interact with other proteins (e.g. protein kinases), which regulate gap junctional communication at several stages of the connexin 'lifecycle', including the trafficking, assembly/disassembly of gap junctional channels in the plasma membrane, connexin turnover, and the gating of gap junctional channels (Lampe \& Lau 2000, Duffy et al. 2002, Herve et al. 2004). Therefore, our and other studies demonstrate that gap junctional proteins may have multiple functions.

We observed inhibition of luteal Cx43 mRNA expression by siRNA in this study, but the decrease was only about $40 \%$ of control. This indicates that the siRNA used in the present experiment did not fully suppress expression of $\mathrm{Cx} 43$. Progesterone secretion was also only 
partially suppressed by siRNA for Cx43 in this study. Cx43 likely is not the only connexin involved in the regulation of steroidogenesis in the $\mathrm{CL}$. In fact, other connexins including Cx26, Cx32, and Cx37 have been detected in luteal tissues in sheep (Grazul-Bilska et al. 1998b, Borowczyk et al. 2006a, 2006b). Cx37 protein was localized to ovine luteal cell borders, indicating that Cx37 may also be involved in the formation of gap junctions between luteal cells, and possibly in the regulation of progesterone secretion (Borowczyk et al. 2006b). Heterologous interactions between connexins have been well characterized indicating that different connexin composition (e.g. Cx26/Cx32 and Cx43/Cx37) may form a functional heterotypic or heteromeric channel (Stauffer 1995, Jiang \& Goodenough 1996, Brink et al. 1997, Weber et al. 2004). Thus, it is very likely that Cx43 may be co-expressed or form heterotypic channels and thus share functions with other connexins in the CL. In organs, such as the liver and pancreas, Cx26 and Cx32 are highly expressed and the integrity of both connexins is necessary for normal glandular secretory function. Interestingly, in Cx32-knockout mice, glandular secretion was significantly reduced; however, Cx26 was still expressed and maintained liver secretory functions (Walcott et al. 2002). This indicates that in the absence of one connexin, some other connexin(s) is(are) sufficient to maintain normal organ function. Therefore, further studies using a combination of siRNA cocktails against several connexins should be performed in luteal cell cultures, in order to clearly demonstrate the role of connexins in the regulation of the CL function. In fact, regulation of luteal function is a complex process (Niswender \& Nett 1994, Milvae et al. 1996, Pate 1996, Niswender et al. 2000, Stouffer 2006); therefore, gap junctional proteins seem to be only a part of the complex mechanism contributing to normal function of the $\mathrm{CL}$.

Our results did not fully support our hypothesis that cell-cell contact affects basal or induced progesterone secretion by luteal cells in vitro. However, we have demonstrated a positive relationship between progesterone production, Cx43 mRNA expression, and the rate of GIC in ovine luteal cells. Therefore, our data suggest that $\mathrm{Cx} 43$ is involved in the regulation of progesterone production by ovine luteal cells. However, future studies should be undertaken using siRNA cocktail for connexin genes to characterize the role of gap junctions and specific connexins in the regulation of progesterone secretion and expression of enzymes controlling steroidogenesis within the $\mathrm{CL}$.

\section{Acknowledgements}

The authors would like to thank Mr James D Kirsch, Mr Kim C Kraft, Mr Robert Weigl, Mr Tim Johnson, Mr Terry Skunberg, and other members of our laboratory for their technical assistance, and Ms Julie Berg for clerical assistance. Supported by USDA NRICGP 2002-35203-11643 grant to ATGB.

\section{References}

Borowczyk E, Johnson ML, Redmer DA, Reynolds LP, Navanukraw C \& Grazul-Bilska AT 2006a Expression of gap junctional connexins 26, 32 and 43 mRNA in ovarian preovulatory follicles and corpora lutea in sheep. Canadian Journal of Physiology and Pharmacology 84 1-9.

Borowczyk E, Johnson ML, Bilski JJ, Borowicz P, Redmer DA, Reynolds LP \& Grazul-Bilska AT 2006b Gap junctional connexin 37 is expressed in sheep ovaries. Endocrine 30 223-230.

Brink PR, Cronin K, Banach K, Peterson E, Westphale EM, Seul KH, Ramanan SV \& Beyer EC 1997 Evidence for heteromeric gap junction channels formed from rat connexin 43 and human connexin 37. American Journal of Physiology 42 C1386-C1396.

Collares-Buzato CB, Leite AR \& Boschero AC 2001 Modulation of gap and adherens junctional proteins in cultured neonatal pancreatic islets. Pancreas 23 177-185.

Davis JS \& Rueda BR 2002 The corpus luteum: an ovarian structure with maternal instincts and suicidal tendencies. Frontiers in Bioscence 7 d1949-d1978.

Del Vecchio RP, Thibodeaux JK, Randel RD \& Hansel W 1994 Interactions between large and small bovine luteal cells in a sequential perfusion co-culture system. Journal of Animal Science 72 963-968.

Del Vecchio RP, Thibodeaux JK \& Hansel W 1995a Contact-associated interactions between bovine luteal cells during the estrous cycle. Domestic Animal Endocrinology 12 25-33.

Del Vecchio RP, Thibodeaux JK, Saatman R \& Hansel W $1995 b$ Interactions between large and small luteal cells collected during the mid- or late-luteal stages of the bovine oestrous cycle. Reproduction Fertility Development 7 35-40.

Duffy HS, Delmar M \& Spray DC 2002 Formation of the gap junction nexus: binding partners for connexins. Journal of Physiology Paris 96 243-249.

Goodenough DA, Goliger JA \& Paul DL 1996 Connexins, connexons, and intercellular communication. Annual Reviews in Biochemistry 65 475-502.

Grazul-Bilska AT, Redmer DA, Bilski JJ, Jablonka-Shariff A, Biondini ME \& Reynolds LP 1995 Proliferation and progesterone production of ovine luteal cells from several stages of the estrous cycle: effects of fibroblast growth factors and luteinizing hormone. Canadian Journal of Physiology and Pharmacology 73 491-500.

Grazul-Bilska AT, Reynolds LP, Kirsch JD \& Redmer DA 1996a Gap junctional intercellular communication of bovine luteal cells from several stages of the estrous cycle: Effects of cyclic adenosine $3^{\prime}, 5^{\prime}$ monophosphate. Biology of Reproduction 54 538-545.

Grazul-Bilska AT, Reynolds LP, Kirsch JD, Bilski JJ \& Redmer DA 1996 b Gap junctional intercellular communication of bovine luteal cells from several stages of the estrous cycle: Effects of prostaglandin F2 $\alpha$, protein kinase C and calcium. Prostaglandins 52 285-302.

Grazul-Bilska AT, Reynolds LP \& Redmer DA 1997a Gap junctions in the ovaries. Biology of Reproduction 57 947-957.

Grazul-Bilska AT, Redmer DA \& Reynolds LP 1997b Cellular interactions within the corpus luteum. Seminars in Reproductive Endocrinology 15 383-393.

Grazul-Bilska AT, Bilski JJ, Giles H, Redmer DA \& Reynolds LP 1998 a Transfection of bovine luteal cells with gap junctional protein connexin 43 (Cx43) antisense oligonucleotide affects progesterone secretion. Biology of Reproduction $\mathbf{5 7}$ 78, abstract 21.

Grazul-Bilska AT, Redmer DA, Bilski JJ, Jablonka-Shariff A, Doraiswamy V \& Reynolds LP 1998 b Gap junctional proteins, connexin 26, 32 and 43 in sheep ovaries throughout the estrous cycle. Endocrine 8 269-279.

Grazul-Bilska AT, Bilski JJ, Doraiswamy V, Reynolds LP \& Redmer DA 2000 Gap junctional intercellular communication (GJIC) in cultured luteal cells from ewes treated with $\mathrm{LH}$ and/or an analog of prostaglandin F2 $\alpha$ (PGF) during the early-luteal phase of the estrous cycle. Biology of Reproduction 62 125, abstract 50. 
Grazul-Bilska AT, Reynolds LP, Bilski JJ \& Redmer DA 2001 Effects of second messengers on gap junctional intercellular communication of ovine luteal cells throughout the estrous cycle. Biology of Reproduction 65 777-783.

Grazul-Bilska AT, Bilski JJ, Johnson ML, Redmer DA \& Reynolds LP 2002 Effects of gap junction function inhibitors on gap junctional intercellular communication (GJIC), connexin (Cx) 43 expression and progesterone (P4) secretion by ovine luteal cells in vitro. Biology of Reproduction $\mathbf{6 6} 285$, abstract 461.

Herve JC, Bourmeyster N \& Sarrouilhe D 2004 Diversity in proteinprotein interactions of connexins: emerging roles. Biochimica Biophysica Acta 1662 22-41.

Hild-Petito S, Ottobre AC \& Hoyer PB 1987 Comparison of subpopulations of luteal cells obtained from cyclic and superovulated ewes. Journal of Reproduction and Fertility 80 537-544.

Jablonka-Shariff A, Grazul-Bilska AT, Redmer DA \& Reynolds LP 1993 Growth and cellular proliferation of ovine corpora lutea throughout the estrous cycle. Endocrinology 133 1871-1879.

Jiang JX \& Goodenough DA 1996 Heteromeric connexons in lens gap junction channels. PNAS 93 1287-1291.

Juengel JL \& Niswender GD 1999 Molecular regulation of luteal progesterone synthesis in domestic ruminants. Journal of Reproduction and Fertility Supplement 54 193-205.

Kirk RE 1982 Experimental Design: Procedures for the Behavioral Sciences, 2nd edn. Belmont, CA: Brooks/Cole.

Kumar NM \& Gilula NB 1996 The gap junction communication channel. Cell 84 381-388.

Lampe PD \& Lau AF 2000 Regulation of gap junctions by phosphorylation of connexins. Archive of Biochemistry and Biophysiology 384 205-215.

Larson DM, Wrobleski MJ, Sagar GDV, Westphale EM \& Beyer EC 1997 Differential regulation of connexin43 and connexin37 in endothelial cells by cell density, growth, and TGF- $\beta 1$. American Journal of Physiology 272 C405-C415.

Leite AR, Carvalho CPF, Furtado AG, Barbosa HCL, Boschero AC \& Collares-Buzato CB 2005 Co-expression and regulation of connexins 36 and 43 in cultured neonatal rat pancreatic islets. Canadian Journal of Physiology and Pharmacology 83 142-151.

Leung PCK \& Steele GL 1992 Intracellular signaling in the gonads. Endocrine Reviews 3 476-498.

McClellan MC, Dieckman MA, Abel JH \& Niswender GD 1975 Luteinizing hormone, progesterone and the morphological development of normal and superovulated corpora lutea in sheep. Cell and Tissue Research 164 291-307.

Meda P 2000 Probing the function of connexin channels in primary tissues. Methods 20 232-244.

Meda P, Pepper MS, Traub O, Willecke K, Gros D, Beyer E, Nicholson B, Paul D \& Orci L 1993 Differential expression of gap junction connexins in endocrine and exocrine glands. Endocrinology 133 2371-2378.

Milvae RA, Hinckley ST \& Carlson JC 1996 Luteotropic and luteolytic mechanisms in the bovine corpus luteum. Theriogenology 45 1327-1349.

Moorby C \& Patel M 2001 Dual functions for connexins: Cx43 regulates growth independently of gap junction formation. Experimental Cell Research 271 238-248.

Morand I, Fonlupt P, Guerrier A, Trouillas J, Calle A, Remy C, Rousset B \& Munari-Silem Y 1996 Cell-to-cell communication in the anterior pituitary: evidence for gap junction-mediated exchanges between endocrine cells and folliculostellate cells. Endocrinology $1373356-3367$.

Munari-Silem Y \& Rousset B 1996 Gap junction-mediated cell-to-cell communication in endocrine glands-molecular and functional aspects: a review. European Journal of Endocrinology 135 251-264.

Naus CC 2002 Gap junctions and tumor progression. Canadian Journal of Physiology and Pharmacology 80 136-141.

Niswender GD \& Nett TM 1994 Corpus luteum and its control in infraprimate species. In The Physiology of Reproduction, pp 781-816. Eds E Knobil \& JK Neil. New York: Raven Press, Ltd.
Niswender GD, Juengel JJ, Silva PJ, Rollyson MK \& McIntush EW 2000 Mechanisms controlling the function and life span of the corpus luteum. Physiology Reviews 80 1-29.

Oyoyo UA, Shah US \& Murray SA 1997 The role of $\alpha 1$ (connexin-43) gap junction expression in adrenal cortical cell function. Endocrinology 138 5385-5396.

Pate JL 1996 Intercellular communication in the bovine corpus luteum. Theriogenology 45 1381-1397.

Pate JL, Nephew KP \& Zarle GS 1987 Cell density influences hormonal responsiveness but not lipoprotein utilization in cultured bovine luteal cells. Molecular and Cellular Endocrinology 53 187-194.

Redmer DA, Grazul-Bilska AT \& Reynolds LP 1991 Contact-dependent intercellular communication of bovine luteal cells in culture. Endocrinology 129 2757-2766.

Redmer DA \& Reynolds LP 1996 Angiogenesis in the ovary. Reviews of Reproduction 1 182-192.

Reynolds LP \& Redmer DA 1999 Growth and development of the corpus luteum. Journal of Reproduction and Fertility Supplement $\mathbf{5 4}$ 182-192.

Reynolds LP, Grazul-Bilska AT \& Redmer DA 2002 Angiogenesis in the female reproductive organs: pathological implications. International Journal of Experimental Pathology 83 151-163.

Rosenberg E, Faris RA, Spray DA, Monfils B, Abreu S, Danishefsky I \& Reid LM 1996 Correlation of expression of connexin mRNA isoforms with degree of cellular differentiation. Cell Adhesion and Communication 4 223-235.

Saez JC, Berthoud VM, Moreno AP \& Spray DC 1993 Gap junctions. Multiplicity of controls in differentiated and undifferentiated cells and possible functional implications. In Advances in Second Messenger and Phosphoprotein Research, pp 163-198. Eds S Shenolikar \& AC Narin. New York: Raven Press, Ltd.

SAS 2005 User's Guide, Statistics 5th edn. Statistical Analysis System Institute, Cary, NC, USA.

Serre-Beinier V, Mas C, Calabrese A, Caton D, Bauquis J, Caille D, Charollais A, Cirulli V \& Meda P 2002 Connexins and secretion. Biology of the Cell 94 477-492.

Shah US \& Murray SA 2001 Bimodal inhibition of connexin 43 gap junctions decreases ACTH-induced steroidogenesis and increases bovine adrenal cell population growth. Journal of Endocrinology 171 199-208.

Sohl G \& Willecke K 2004 Gap junctions and the connexin protein family. Cardiovascular Research 62 228-232.

Stauffer KA 1995 The gap junction proteins b1-connexin (connexin-32) and b2-connexin (connexin-26) can form heteromeric hemichannels. Journal of Biological Chemistry 270 6768-6772.

Stouffer RL 2006 Structure, function and regulation of the corpus luteum. In Knobil and Neill's Physiology of Reproduction, pp 475-526. Ed. JD Neill. New York: Elsevier Academic Press.

Walcott B, Moore LC, Birzgalis A, Claros N, Valiunas V, Ott T, Willecke K \& Brink PR 2002 Role of gap junctions in fluid secretion of lacrimal glands. American Journal of Physiology Cell Physiology 282 501-507.

Weber PA, Chang H, Spaeth KE, Nitsche JM \& Nicholson BJ 2004 The permeability of gap junction channels to probes of different size is dependent on connexin composition and permeant-pore affinities. Biophysiology Journal 87 958-973.

Wynn J, Shah U \& Murray SA 2002 Redistribution of connexin 43 by cAMP: a mechanism for growth control in adrenal cells. Endocrine Research 28 663-668.

Yamasaki H \& Naus CCG 1996 Role of connexin genes in growth control. Carcinogenesis 17 1199-1213.

Received 29 August 2006

First decision 27 September 2006

Revised manuscript received 6 November 2006

Accepted 29 November 2006 